\title{
Risk Factors for Delirium During Acute and Subacute Stages of Various Disorders in Patients Admitted to Rehabilitation Units
}

\author{
Soyeon Jang, MD, Kwang-Ik Jung, MD, PhD, Woo-Kyoung Yoo, MD, PhD, \\ Myung Hun Jung, MD, PhD, Suk Hoon Ohn, MD, PhD \\ Department of Physical Medicine and Rehabilitation, Hallym University Sacred Heart Hospital, \\ Hallym University College of Medicine, Anyang, Korea
}

\begin{abstract}
Objective To assess the risk factors for delirium in patients admitted to a rehabilitation unit for acute or subacute neurological or musculoskeletal disorders.

Methods We reviewed the medical records of 537 patients admitted to a rehabilitation unit and selected 398 patients in the acute or subacute stage of various neurological or musculoskeletal disorders. Among them, patients who had suffered from delirium were categorized into the delirium group $(n=65)$, and the other patients were categorized into the non-delirium group $(\mathrm{n}=333)$. As potential risk factors for delirium, the patients' diagnosis, underlying disease, demographic data, hospital stay duration, surgery, and laboratory findings were reviewed, and the differences between the two groups with respect to independent risk factors were analyzed.

Results The average age in the delirium group was higher; the hospital stay and pre-transfer periods were longer. A large proportion of the patients were admitted for musculoskeletal disorders, and many patients had diabetes mellitus, dementia, and depression as underlying diseases. Laboratory tests revealed increases in the white blood cells (WBC), glucose, blood urea nitrogen (BUN), total bilirubin, aspartate transaminase (AST), erythrocyte sedimentation rate (ESR), and C-reactive protein (CRP) levels in the delirium group, while the hemoglobin, calcium, phosphorus, protein, albumin, and potassium levels were decreased. Depression, musculoskeletal disorders, traumatic brain injury, elevated WBC, BUN, AST, and CRP levels, and decreased potassium and phosphorus levels were identified as independent risk factors for delirium.

Conclusion Risk factors treatable before delirium onset were identified in rehabilitation patients in acute and subacute stages of various disorders. Early diagnosis and prevention of these risk factors could decrease delirium occurrence and increase rehabilitation effectiveness.
\end{abstract}

Keywords Delirium, Risk factors, Rehabilitation

Received March 21, 2016; Accepted May 23, 2016

Corresponding author: Suk Hoon Ohn

Department of Physical Medicine and Rehabilitation, Hallym University Sacred Heart Hospital, Hallym University College of Medicine, 22 Gwanpyeong-ro 170beon-gil, Dongan-gu, Anyang 14068, Korea. Tel: +82-31-380-3860, Fax: +82-31-380-3864, E-mail: ohnsh@hallym.ac.kr

ORCID: Soyeon Jang (http://orcid.org/0000-0002-1124-2457); Kwang-Ik Jung (http://orcid.org/0000-0003-1998-1921); Woo-Kyoung Yoo (http://orcid. org/0000-0002-1273-0647); Myung Hun Jung (http://orcid.org/0000-0003-2393-3930); Suk Hoon Ohn (http://orcid.org/0000-0002-1139-1946).

(c) This is an open-access article distributed under the terms of the Creative Commons Attribution Non-Commercial License (http://creativecommons.org/ licenses/by-nc/4.0) which permits unrestricted noncommercial use, distribution, and reproduction in any medium, provided the original work is properly cited. Copyright (c) 2016 by Korean Academy of Rehabilitation Medicine 


\section{INTRODUCTION}

Delirium is an acute state of confusion, and it can be defined as reduced ability to direct, focus, sustain, and shift attention and orientation to the environment. There is an accompanying change in at least one other area that may include memory and learning, disorientation, alteration in language, or perceptual disturbance. Delirium develops over a short period of time, usually hours to a few days, and tends to fluctuate during the course of the day [1]. Delirium often results in poor outcomes, including not only high mortality but also increased hospital stay duration, cost of care, institutional placement rate, and functional and cognitive decline [2-4]. Therefore, delirium must be prevented or managed properly for achieving a successful rehabilitation outcome.

In patients with predisposing risk factors, delirium is caused by medical illness, complications, invasive procedures, and environmental stress. Therefore, delirium can be a sign of underlying diseases in rehabilitation patients [5]. Delirium significantly impedes the rehabilitation process, and it is important to prevent delirium by discerning its risk factors $[6,7]$. Most patients in rehabilitation units are elderly and they exhibit known deliriuminducing factors besides age. However, several recent meta-analyses have not identified consistent risk factors for delirium. Advanced age, dementia, and electrolyte imbalance have been reported as risk factors uniformly, but other factors including sex, medical illness, and psychological problems have been reported discrepantly [8-12]. To date, studies of delirium risk factors have only been conducted for specific diseases without considering each disease as a potential risk factor. Therefore, comprehensive research on delirium-causing factors including all diseases is needed. The authors conducted a study of the major delirium-causing risk factors in rehabilitation patients in subacute and acute stages of various neurological or musculoskeletal disorders.

\section{MATERIALS AND METHODS}

\section{Subjects}

The present study included patients transferred to the rehabilitation unit of the Hallym University Sacred Heart Hospital (Anyang, Korea) between January 2014 and October 2015. It was a retrospective study based on the review of medical records of each patient. To analyze the prevalence of delirium in patients admitted to the rehabilitation unit, discharged patients who had been transferred to the rehabilitation unit from other hospitals were excluded from the analysis, because they were considered to be in the chronic or stable stage of disease. Only patients transferred to the rehabilitation unit from a different unit of the hospital were included in the study. All included patients were older than 19 years (Fig. 1).

\section{Methods}

If a patient had new-onset disorientation, hallucination, cognitive dysfunction, sleep disturbance, anxiety, hyperactivity, or hypoactivity, the patient was referred to psychiatrists who had extensive experience in the diagnosis of delirium, which was performed according to the Diagnostic and Statistical Manual of Mental Disorders, fifth edition (DSM-V), definition [1]. The DSM-V diagnostic criteria for delirium are as follows: (A) a disturbance in attention (i.e., reduced ability to direct, focus, sustain, and shift attention) and awareness (reduced orientation to the environment) is present; (B) the disturbance develops over a short period of time (usually hours to days), represents an acute change from baseline attention and awareness, and tends to fluctuate in severity during the course of the day; (C) an additional disturbance in cognition is present (e.g., memory deficit, disorientation, disruptions of language, visuospatial ability, or perception); (D) the disturbances in criteria (A) and (C) are not better explained by a pre-existing, established or evolving neurocognitive disorder, and do not occur in the context of a severely reduced level of arousal, such as coma; (E) there is evidence from the history, physical examination, or laboratory findings that the disturbance is a direct physiological consequence of another medical condition, substance intoxication or withdrawal (i.e. due to a drug of abuse or a medication), or exposure to a toxin, or is due to multiple etiologies.

Assessments of risk factors for delirium were derived from the medical records retrospectively in all patients. The following factors identified as delirium risk factors in previous research were studied: demographic data (age and sex), hospital stay duration (pre-transfer days, posttransfer days, and days of ICU stay), surgery, reason for admission, underlying disease, and laboratory findings. If a patient was admitted presenting with two or more 


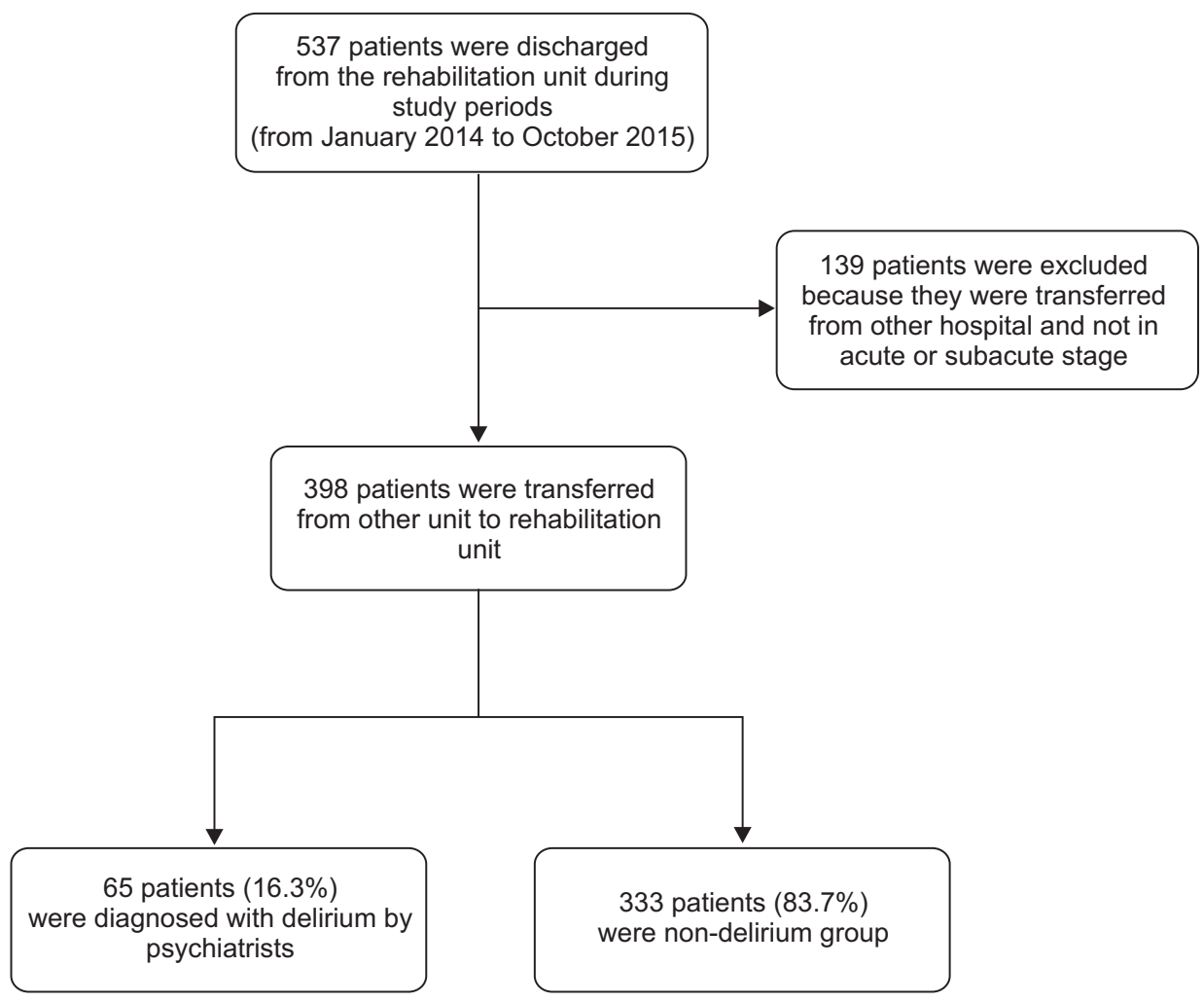

Fig. 1. Participant flow chart. Flow chart describes the progress of patients belonging to the delirium group or the non-delirium group. diseases, all diseases were considered as potential risk factors. Only surgeries and admissions to the ICU during the study period were considered as risk factors. In the delirium group, only laboratory findings obtained within one week from the time of delirium diagnosis were considered and analyzed. In the non-delirium group, laboratory findings from the time of transfer to the rehabilitation unit were considered and analyzed. All patients provided written informed consent for their participation in this study, which was approved by the Institutional Review Board of the Hallym University Sacred Heart Hospital (IRB No. 2015-I136).

\section{Statistical analysis}

Age, hospital stay duration, and blood tests in the two groups were analyzed using the independent t-test. Data such as sex, history, and surgery were analyzed using the chi-square or Fisher exact test. The logistic regression model included variables that differed between the two groups-age, underlying depression, dementia and diabetes mellitus (DM), admission for musculoskeletal disorder, hemorrhagic or ischemic stroke, white blood cell (WBC), hemoglobin (Hb), hematocrit (Hct), platelet, glucose, blood urea nitrogen (BUN), protein, albumin, total bilirubin, total calcium (Ca), phosphorus $(\mathrm{P})$, aspartate aminotransferase (AST), lactate dehydrogenase (LD), potassium (K), and C-reactive protein (CRP); the known risk factors for delirium - age, sex, surgery on admission, admission for traumatic brain injury (TBI) and sodium (Na); and underlying diseases that proved to have an effect on the reason for admission by chi-square test (hypertension, DM, dyslipidemia, depression, dementia, stroke, chronic alcoholism) and calculated odds ratio (OR). SPSS software ver. 22.0 (IBM, Armonk, NY, USA) was used for analysis, and the statistical significance was set to a p-value $<0.05$.

\section{RESULTS}

During the study period, 537 patients were discharged. After excluding the 139 patients who had been transferred from other hospitals, 398 patients were selected as subjects (Fig. 1). Delirium occurred in 65 (16.3\%) out of the initial 398 subjects (delirium group: 65/398, 16.3\%), and the remaining 333 subjects were categorized into the non-delirium group (non-delirium group: 333/398, 83.7\%). The participants' demographic data are shown in Table 1. The average age of the subjects in the delirium group was $69.3 \pm 13.9$ years, which was significantly higher 
Table 1. Demographic characteristics of the subjects

\begin{tabular}{|lccc|}
\hline \multicolumn{1}{c}{ Characteristic } & Delirium & Non-delirium & t-value or $\chi^{2}$ \\
\hline Age (yr) & $69.3 \pm 13.9^{*}$ & $63.5 \pm 16.5$ & $-2.641^{\text {a) }}$ \\
\hline Sex (male:female) & $35: 30$ & $169: 164$ & $0.209^{\text {b) }}$ \\
\hline Total hospital stay (day) & $44.8 \pm 26.1^{*}$ & $38.3 \pm 19.4$ & $-2.317^{\text {a) }}$ \\
\hline Pre-transfer days & $29.1 \pm 23.9^{*}$ & $20.3 \pm 15.1$ & $-2.860^{\text {a) }}$ \\
\hline Post-transfer days & $15.6 \pm 9.1$ & $18.0 \pm 10.6$ & $1.760^{\text {a) }}$ \\
\hline ICU stay (day) & $6.5 \pm 7.7$ & $5.4 \pm 8.2$ & $-0.994^{\text {a) }}$ \\
\hline Surgery & $39(60.0)$ & $183(55.0)$ & $0.561^{\text {b) }}$ \\
\hline
\end{tabular}

Values are presented as mean \pm standard deviation or number (\%).

${ }^{*} \mathrm{p}<0.05$ by independent $\mathrm{t}$-test. ${ }^{\mathrm{a})}$ Independent $\mathrm{t}$-test (t-value), ${ }^{\mathrm{b})}$ chi-square test or Fisher exact test $\left(\chi^{2}\right)$.

Table 2. Reason for admission

\begin{tabular}{lccc}
\hline \multicolumn{1}{c}{ Variable } & Delirium & $\begin{array}{c}\text { Non- } \\
\text { delirium }\end{array}$ & $\chi^{2}$ \\
\hline $\begin{array}{l}\text { Musculoskeletal disorder } \\
\text { (except for spine disorder) }\end{array}$ & $22(33.8)^{*}$ & $57(17.1)$ & 9.567 \\
Spine disorder & $13(20.0)$ & $52(15.6)$ & 0.765 \\
TBI & $13(20.0)$ & $52(15.6)$ & 0.765 \\
Stroke (hemorrhagic) & $10(15.4)^{*}$ & $96(28.8)$ & 5.031 \\
SCI & $4(6.2)$ & $19(5.7)$ & 0.020 \\
Stroke (ischemic) & $2(3.1)^{*}$ & $42(12.6)$ & 5.029 \\
Aspiration pneumonia & $2(3.1)$ & $6(1.8)$ & 0.449 \\
Hypoxic brain injury & $1(1.5)$ & $3(0.9)$ & 0.222 \\
Drug induced dystonia & $1(1.5)$ & $0(0.0)$ & 5.136 \\
Guillain-Barre syndrome & $0(0.0)$ & $6(1.8)$ & 1.189 \\
Brain tumor/abscess & $0(0.0)$ & $4(1.2)$ & 0.789 \\
Seizure & $0(0.0)$ & $2(0.6)$ & 0.392 \\
Encephalitis & $0(0.0)$ & $2(0.6)$ & 0.392 \\
Dementia & $0(0.0)$ & $1(0.3)$ & 0.196 \\
Normal pressure & $0(0.0)$ & $1(0.3)$ & 0.196
\end{tabular}

hydrocephalus

Values are presented as number (\%).

$\mathrm{TBI}$, traumatic brain injury; SCI, spinal cord injury.

${ }^{*} \mathrm{p}<0.05$ by chi-square test or Fisher exact test.

than the average age of the subjects in the non-delirium group (63.5 \pm 16.5 years; $p=0.009$ ). Days of hospital stay $(\mathrm{p}=0.021)$ and pre-transfer days $(\mathrm{p}=0.005)$ were significantly higher in the delirium group; while sex, posttransfer days, days of ICU stay, and surgery did not show significant differences.

The reasons for admission were as follows: musculoskeletal disorder (except for spine disorder), TBI, hemorrhagic stroke, ischemic stroke, spine disorder, spinal cord injury (SCI), hypoxic brain damage, brain tumor or
Table 3. Underlying disease

\begin{tabular}{lccr}
\hline \multicolumn{1}{c}{ Variable } & Delirium & $\begin{array}{c}\text { Non- } \\
\text { delirium }\end{array}$ & $\chi^{2}$ \\
\hline Hypertension & $41(63.1)$ & $173(52.0)$ & 2.708 \\
Diabetes mellitus & $22(33.8)^{*}$ & $73(21.9)$ & 4.255 \\
Stroke & $13(20.0)$ & $52(15.6)$ & 0.765 \\
Dementia & $10(15.4)^{*}$ & $19(5.7)$ & 7.542 \\
Dyslipidemia & $9(13.8)$ & $50(15.0)$ & 0.059 \\
Chronic alcoholism & $7(10.8)$ & $22(6.6)$ & 1.395 \\
Depression & $6(9.2)^{*}$ & $6(1.8)$ & 10.264 \\
Parkinson disease & $3(4.6)$ & $10(3.0)$ & 0.447 \\
\hline
\end{tabular}

Values are presented as number (\%).

${ }^{*} \mathrm{p}<0.05$ by chi-square test or Fisher exact test.

abscess, dementia, seizure, encephalitis, Guillain-Barre syndrome, drug induced dystonia, normal pressure hydrocephalus, and aspiration pneumonia. The number of patients who were admitted with musculoskeletal disorder $(p=0.002)$ was significantly higher in the delirium group, while the non-delirium group showed a significantly higher number of patients who were admitted with hemorrhagic stroke $(\mathrm{p}=0.025)$ and ischemic stroke ( $\mathrm{p}=0.025)$ (Table 2). The occurrence frequency of delirium was significantly higher in patients who had DM $(p=0.039)$, dementia $(p=0.015)$, or depression $(p=0.015)$ as underlying diseases (Table 3 ).

According to the complete blood count test, WBC $(\mathrm{p}<0.001)$, neutrophil count $(\mathrm{p}<0.001)$, and neutrophil percentage $(p<0.001)$ were significantly increased in the delirium group. The percentage of lymphocytes $(p<0.001)$, monocytes $(p=0.002)$, eosinophils $(p=0.007)$, and basophils $(\mathrm{p}<0.001)$, platelets $(\mathrm{p}=0.001)$, and the $\mathrm{Hb}(\mathrm{p}=0.038)$ and Hct $(\mathrm{p}=0.006)$ levels were reduced in 
the delirium group. Serologic tests in the delirium group showed significant increases in the levels of glucose ( $\mathrm{p}=0.010)$, BUN ( $\mathrm{p}=0.036)$, total bilirubin $(\mathrm{p}=0.006)$, AST $(\mathrm{p}=0.009)$, and LD $(\mathrm{p}=0.002)$, while the $\mathrm{Ca}, \mathrm{P}$, protein, albumin, and K levels were significantly reduced. The erythrocyte sedimentation rate (ESR; $\mathrm{p}=0.006$ ) and CRP levels $(\mathrm{p}<0.001)$ were significantly higher in the delirium group (Table 4).

Table 4. Comparison between the delirium group and the non-delirium group in terms of laboratory findings

\begin{tabular}{|c|c|c|c|}
\hline Variable & Delirium & Non-delirium & t-value \\
\hline \multicolumn{4}{|l|}{ Complete blood count } \\
\hline $\operatorname{WBC}\left(/ 10^{3} / \mu \mathrm{L}\right)$ & $9.98 \pm 4.24^{*}$ & $7.52 \pm 2.51$ & -4.522 \\
\hline Neutrophil count $\left(/ 10^{3} / \mu \mathrm{L}\right)$ & $7.78 \pm 4.32^{*}$ & $4.97 \pm 2.30$ & -5.092 \\
\hline Neutrophil (\%) & $74.57 \pm 11.72 *$ & $64.01 \pm 11.93$ & -6.547 \\
\hline Lymphocyte (\%) & $15.20 \pm 9.12^{*}$ & $23.58 \pm 9.58$ & 6.499 \\
\hline Monocyte (\%) & $6.44 \pm 2.34^{*}$ & $7.58 \pm 2.82$ & 3.069 \\
\hline Eosinophil (\%) & $2.46 \pm 2.74^{*}$ & $3.43 \pm 2.60$ & 2.722 \\
\hline Basophil (\%) & $0.31 \pm 0.26^{*}$ & $0.50 \pm 0.32$ & 5.022 \\
\hline $\mathrm{Hb}(\mathrm{g} / \mathrm{dL})$ & $11.19 \pm 1.70^{*}$ & $11.66 \pm 1.64$ & 2.080 \\
\hline $\operatorname{Hct}(\%)$ & $32.90 \pm 4.73^{*}$ & $34.56 \pm 4.49$ & 2.761 \\
\hline Platelet $\left(/ 10^{3} / \mu \mathrm{L}\right)$ & $245.25 \pm 137.64^{*}$ & $298.17 \pm 113.90$ & 3.306 \\
\hline \multicolumn{4}{|l|}{ Serology } \\
\hline Glucose (mg/dL) & $128.45 \pm 40.00^{*}$ & $114.34 \pm 40.17$ & -2.592 \\
\hline $\mathrm{Ca}(\mathrm{mg} / \mathrm{dL})$ & $8.42 \pm 0.63^{*}$ & $8.79 \pm 0.517$ & 4.489 \\
\hline $\mathrm{P}(\mathrm{mg} / \mathrm{dL})$ & $3.17 \pm 1.03^{*}$ & $3.69 \pm 0.76$ & 3.928 \\
\hline Uric acid (mg/dL) & $3.74 \pm 1.58$ & $3.75 \pm 1.52$ & 0.045 \\
\hline BUN (mg/dL) & $18.29 \pm 11.52^{*}$ & $15.13 \pm 7.30$ & -2.135 \\
\hline $\mathrm{Cr}(\mathrm{mg} / \mathrm{dL})$ & $0.9149 \pm 1.10$ & $0.74 \pm 0.51$ & -1.254 \\
\hline Cholesterol (mg/dL) & $149.05 \pm 45.20$ & $158.03 \pm 38.50$ & 1.670 \\
\hline Protein $(\mathrm{g} / \mathrm{dL})$ & $6.09 \pm 0.83^{*}$ & $6.47 \pm 0.70$ & 3.419 \\
\hline Albumin (g/dL) & $3.49 \pm 0.44^{*}$ & $3.67 \pm 0.45$ & 3.028 \\
\hline Total bilirubin (mg/dL) & $0.83 \pm 0.68^{*}$ & $0.58 \pm 0.34$ & -2.842 \\
\hline AST (IU/L) & $37.09 \pm 24.86^{*}$ & $30.37 \pm 17.35$ & -2.642 \\
\hline ALT (IU/L) & $27.55 \pm 26.85$ & $27.23 \pm 35.38$ & -0.070 \\
\hline $\operatorname{ALP}(\mathrm{U} / \mathrm{L})$ & $115.94 \pm 118.75$ & $125.72 \pm 93.40$ & 0.736 \\
\hline LD (IU/L) & $499.37 \pm 153.03^{*}$ & $444.77 \pm 122.73$ & -3.143 \\
\hline GGT (IU/L) & $55.46 \pm 56.79$ & $63.32 \pm 102.44$ & 0.600 \\
\hline $\mathrm{Na}(\mathrm{mmol} / \mathrm{L})$ & $139.25 \pm 4.31$ & $139.71 \pm 3.47$ & 0.815 \\
\hline $\mathrm{K}(\mathrm{mmol} / \mathrm{L})$ & $3.83 \pm 0.52 *$ & $4.19 \pm 0.48$ & 5.498 \\
\hline $\mathrm{Cl}(\mathrm{mmol} / \mathrm{L})$ & $102.63 \pm 4.36$ & $102.19 \pm 3.46$ & -0.776 \\
\hline Total $\mathrm{CO}_{2}(\mathrm{mmol} / \mathrm{L})$ & $2.76 \pm 0.34$ & $23.34 \pm 2.90$ & 1.856 \\
\hline \multicolumn{4}{|l|}{ Others } \\
\hline ESR (mm/hr) & $43.71 \pm 26.37^{*}$ & $29.20 \pm 20.66$ & -2.945 \\
\hline $\mathrm{CRP}(\mathrm{mg} / \mathrm{L})$ & $61.91 \pm 76.16^{*}$ & $14.68 \pm 23.68$ & -4.954 \\
\hline
\end{tabular}

Values are presented as mean \pm standard deviation.

WBC, white blood cells; Hb, hemoglobin; Hct, hematocrit; BUN, blood urea nitrogen; AST, aspartate aminotransferase; ALT, alanine aminotransferase; ALP, alkaline phosphatase; LD, lactate dehydrogenase; GGT, gamma glutamyl transferase; ESR, erythrocyte sedimentation rate; CRP, C-reactive protein.

${ }^{*} \mathrm{p}<0.05$ by independent $\mathrm{t}$-test. 
Table 5. Risk factors for delirium

\begin{tabular}{lccc}
\hline \multicolumn{1}{c}{ Variable } & B & p-value & OR (95\% CI) \\
\hline Underlying depression & 2.067 & $0.006^{*}$ & $7.899(1.829-34.110)$ \\
\hline Admission for musculoskeletal disorder & 1.122 & $0.009^{*}$ & $3.071(1.322-7.132)$ \\
\hline Admission for TBI & 1.072 & $0.018^{*}$ & $2.922(1.200-7.111)$ \\
WBC & 0.191 & $0.003^{*}$ & $1.210(1.068-1.372)$ \\
BUN & 0.059 & $0.006^{*}$ & $1.061(1.017-1.107)$ \\
AST & 0.021 & $0.012^{*}$ & $1.021(1.005-1.037)$ \\
CRP & 0.014 & $0.001^{*}$ & $1.015(1.006-1.023)$ \\
K & -1.935 & $<0.001^{*}$ & $0.144(0.064-0.327)$ \\
P & -0.511 & $0.036^{*}$ & $0.600(0.372-0.966)$ \\
Albumin & 0.859 & 0.068 & $2.360(0.940-5.928)$ \\
\hline Admission for stroke (ischemic) & -1.256 & 0.117 & $0.285(0.059-1.370)$ \\
\hline
\end{tabular}

B, beta coefficient; OR, odds ratio; CI, confidence interval; TBI, traumatic brain injury; WBC, white blood cells; BUN, blood urea nitrogen; AST, aspartate aminotransferase; CRP, C-reactive protein.

${ }^{*} \mathrm{p}<0.05$ by logistic regression analysis.

ESR was excluded from the logistic regression analysis because it had several missing data. Only WBC was included in the logistic regression analysis model because the significant increase in WBC along with increases in neutrophil count and percentage could have been the reason for significant reductions in the other components (lymphocytes, monocytes, eosinophils, and basophils). The OR was the highest in cases in which depression was the underlying disease $(\mathrm{p}=0.006, \mathrm{OR}=7.899)$. Admissions due to musculoskeletal disorder and TBI had significant OR of $3.071(\mathrm{p}=0.009)$ and $2.922(\mathrm{p}=0.018)$, respectively. Among the laboratory findings, the WBC $(\mathrm{p}=0.003, \mathrm{OR}=1.210)$, BUN $(\mathrm{p}=0.006, \mathrm{OR}=1.061)$, AST $(\mathrm{p}=0.012, \mathrm{OR}=1.021)$, and CRP $(\mathrm{p}=0.001, \mathrm{OR}=1.015)$ levels showed significant positive correlations with the increase in the risk of delirium. The $\mathrm{K}(\mathrm{p}<0.001, \mathrm{OR}=0.144)$ and $\mathrm{P}$ ( $\mathrm{p}=0.036, \mathrm{OR}=0.600$ ) levels in blood showed negative correlations with delirium occurrence (Table 5).

\section{DISCUSSION}

DSM-V was used in this research to diagnose delirium. The criteria for delirium in DSM-V underwent a substantial change by narrowing the spectrum of arousal states in which delirium can be identified [13]. According to a previous research, the prevalence of delirium was $14 \%-56 \%$ in internal medicine inpatients based on the criteria for delirium in DSM-III [8], and 5\%-20\% in patients in elderly hospital settings based on the criteria in DSM-IV [14-
16]. The present study, which used the criteria in DSM-V, showed a prevalence of $16.3 \%$, similar to the results of a previous research.

Delirium is rarely caused by a single factor. In most cases, the complex interaction between patients' underlying conditions (cognitive impairment, old age, alcoholism, visual impairment, etc.) and factors within the hospital (medication, invasive procedure, etc.) causes delirium. The occurrence frequency of delirium increases as the number of underlying diseases increases [7,17]. According to a meta-analysis by Elie et al. [9], the four major underlying diseases in patients suffering from delirium are dementia, severe internal disease, alcoholism, and depression. Pompei et al. [18] showed that delirium occurred in patients with cognitive impairment, associated diseases, depression, and alcoholism. The results of the present study revealed that the risk of delirium increased in the presence of DM, dementia, and depression as underlying diseases. Logistic regression analysis showed that underlying depression had the highest OR, and therefore, it is the most potential factor that increases the risk of delirium. Depression has been confirmed to be a strong risk factor for delirium in all previous studies $[9,19]$. Patients with depression require closer observation during rehabilitation. This study did not take into account the effects of antidepressants in patients who had taken them previously.

Aging has been identified as the single biggest risk factor for the development of delirium in a previous re- 
search [20]. Among the people in the Netherlands who received nursing home care, delirium was reported in $1 \%-2 \%$ of the population aged over 65 years and in $10 \%$ of the population aged over 85 years [21]. In stroke patients, age over 65 years has been reported to be an independent factor for causing delirium [22]. The average age in the delirium group (69.3 years) was statistically significantly higher than that in the non-delirium group (63.5 years) in the present study. However, in the present study, age was not an independent risk factor in the logistic regression analysis. To confirm multicollinearity, the correlation coefficient for age was analyzed with all other variables, and the result $(<0.4)$ did not show a statistically significant correlation. Although it was not shown to be an independent risk factor in this study, age is an important factor nonetheless, because most underlying diseases (e.g., hypertension, DM, and dementia) that are considered to be independent variables in the clinical aspect of this study are age-related geriatric problems. Therefore, treatment of the underlying geriatric disease is important for the prevention or treatment of delirium. Previous studies have reported contrasting effects of gender on delirium, stating that delirium occurrence is higher in either males $[9,23,24]$ or females [25]. However, the present study showed no significant differences between the sex ratios in the two groups $(\mathrm{p}=0.648)$.

Previous reports are not consistent about whether surgery is a delirium-causing factor $[23,26,27]$, and some researchers suggest that delirium occurs in patients who have pre-operative cognitive dysfunction, sedentary life style, low weight, or delayed postoperative ambulation combined with surgery [28-31]. Although surgery was not an independent risk factor for delirium in the present study, the significant increases in the WBC, ESR, CRP, and BUN levels, and the significant decrease in the $\mathrm{K}$ levels in the delirium group suggest that surgery, instead of being an independent factor, increases the risk of delirium indirectly through secondary factors such as postoperative infection, inflammation, dehydration, and electrolyte imbalance. This finding indicates that postoperative care is important in rehabilitation patients.

Most of the previous researches on delirium have focused on patients with a single specific disease. The present study is significant as it included all patients in acute and subacute stages of various disorders and who were transferred to the rehabilitation unit. Musculoskeletal disorder was the most common delirium-causing disease in the delirium group, where hip fracture was present in 62 out of the 70 patients (88.6\%). According to Kamel et al. [29], a delay in ambulation after a hip fracture not only caused delirium but also pneumonia, and it was the reason for long-term admission. It is not possible to state with certainty that delirium was caused in these subjects by delayed ambulation, because time to ambulation was not taken into account. However, it is important to encourage early ambulation in patients based on the results of the previous research.

Hemorrhagic or ischemic stroke was present in only a small percentage of patients in the delirium group in this study, and it was not identified as a risk factor in the logistic regression analysis. According to McManus et al. [32], stroke itself is a risk factor for delirium, and lesion location, lesion size, cause of stroke, as well as complications such as decreased cerebral perfusion, cerebral edema, and aspiration pneumonia, were related to the occurrence of delirium. Therefore, both initial stroke treatment and rehabilitation can play a role in preventing delirium after a stroke. The risk of delirium would be reduced if a patient was treated in a stroke unit that had well-established initial stroke treatment and rehabilitation programs. The recently published Korean stroke rehabilitation guidelines recommend that acute stroke patients should be evaluated for rehabilitation within 72 hours of admission and rehabilitation should be started as soon as possible once the patient is medically stable [33]. The hospital where the present research was conducted also places all acute stroke patients into an early rehabilitation program after consulting the physiatrist within 24 hours of admission. Since the prevalence of delirium was reduced owing to the well-established stroke rehabilitation program, it is possible that the rehabilitation program was the reason why stroke was not identified as an independent risk factor for delirium in this study. In contrast, TBI was confirmed as a risk factor for delirium. Delirium may result from brain injury itself or from associated medical complications that predispose the patient to develop delirium [34]. Therefore, if TBI patients receive treatment including rehabilitation during the early part of their stay in the specialized unit, the occurrence of delirium may decrease.

Various medical conditions affect the development of delirium. In the study of Dickson [35], the most frequent 
laboratory abnormality was hypoalbuminemia. The most common chronic medical problems included DM and cardiovascular disease, while infections and trauma were the most common acute problems. In the present study, the two groups showed significant differences in the $\mathrm{WBC}, \mathrm{Hb}$, Hct, platelet, glucose, $\mathrm{Ca}, \mathrm{P}, \mathrm{BUN}$, protein, albumin, total bilirubin, AST, LD, K, ESR, and CRP levels in blood. The WBC, ESR, and CRP levels in the delirium group indicated increased inflammation or infection, which is in agreement with previous studies that reported infection as a major cause of delirium [36,37]. In particular, WBC and CRP have been identified as independent risk factors for delirium with OR of 1.210 and 1.015, respectively. Since these two factors are correctable, it is important to actively treat and prevent infections in order to prevent delirium. Patients suffering from delirium showed significantly lower levels of $\mathrm{Hb}$ and Hct, indicative of hypoxia and anemia, which in turn can reduce the acetylcholine concentration in the cerebrum and produce delirium [38]. Brauer et al. [38] have reported electrolyte imbalance and metabolic disorders as risk factors for delirium. Hyponatremia is the most common electrolyte disorder present in hospitalized patients and a known risk factor for delirium [39]. However, the results of the present study showed no significant difference in the Na levels between the two groups, and instead they indicated low levels of $\mathrm{K}$ and $\mathrm{P}$ as independent risk factors related to the onset of delirium. The BUN levels in the delirium group were significantly higher and were identified as an independent risk factor for delirium with an OR of 1.06. Inouye et al. [40] stated that a high BUN/Cr ratio was one of the four independent underlying factors along with cognitive impairment, severe disorder, and visual impairment. An increase in BUN levels is related to dehydration. Since low levels of $\mathrm{K}$ and $\mathrm{P}$ are caused by a deficit of fluid supply, including electrolytes, it is important to supply fluids carefully in order to prevent delirium. Since hypophosphatemia can cause muscle weakening and damage, it is a crucial factor that needs to be corrected in rehabilitation patients who have low muscle strength.

A number of variables examined in this study are thought to increase or decrease indirectly, depending on their interactions with the other factors. The significant decrease in platelets is not equivalent to thrombocytopenia in patients with delirium, but rather can be caused by the postoperative state, anemia, or infection. The albumin and protein levels were reduced in the delirium group; however, they were not identified as independent risk factors for delirium in this study. It is possible that low Ca levels in the delirium group were a secondary effect of reduction in the albumin levels.

Delirium negatively affects recovery from a disease. Inouye and Charpentier [17] showed that delirium is an independent prognostic factor that affects the length of hospitalization even after adjusting for other factors such as age, sex, dementia, severity of disease, and ability to carry out daily life activities. In the present study, the total days of hospital stay and pre-transfer days were higher in the delirium group, while there was no difference in post-transfer days. Fifty-eight of the 65 patients suffering from delirium were diagnosed with delirium before being transferred to the rehabilitation unit. The extension of total days of hospital stay in the delirium group was in part due to delirium before the transfer. If delirium is prevented or diagnosed early, transfer to a rehabilitation unit may be completed sooner, giving the patient sufficient opportunity for rehabilitation. The patient's treatment costs will also be reduced.

To the best of our knowledge, the present study of delirium was the first such study in Korea that involved patients in acute and subacute stages of various diseases as subjects. The present study is highly significant because the authors considered the risk factors for delirium from various angles. Risk factors for delirium were evaluated based on the patients' histories, reasons for admission, and laboratory findings as well as demographic data. Another significance is that the study was conducted in a well-established rehabilitation unit that had a system for multidisciplinary management where physiatrists actively participate in the management of all diseases in acute stages requiring rehabilitation. Since delirium is heavily affected by the patient's environment, our study could have produced different results if it had been conducted in a hospital that did not have a system for multidisciplinary management, as was the case in previous studies. In the future, it is important to conduct research for assessing the general prognosis of delirium in cases in which delirium is caused by various diseases as well as for developing an outcome scale that can be used in all diseases.

Nevertheless, this study had several limitations. First, 
unlike patients presenting with hyperactive delirium symptoms at the time of diagnosis, patients with hypoactive delirium, who have restricted communication abilities, could have had a delay in diagnosis after their delirium subtype had changed from hypoactive to hyperactive. Second, there is a possibility that the medical histories of patients were incomplete, since the research was retrospective in nature. Third, medication was not considered as a risk factor for delirium in the present study because there are several types of medication and there are no rules that doctors must abide by while selecting drugs for the same symptoms even in the same rehabilitation unit. Therefore, the authors considered that including medication as a factor in this retrospective study could confound the results. Fourth, multiple reasons for admission (aspiration pneumonia, hypoxic brain injury, drug-induced dystonia, Guillain-Barre syndrome, brain tumor/abscess, seizure, encephalitis, dementia, and normal pressure hydrocephalus) were present in fewer than 10 cases, which is a very small number. But, these factors should not be disregarded.

In conclusion, this study identified depression, admission for musculoskeletal disorder, admission for TBI, elevated WBC, CRP, BUN, and AST levels, and low $\mathrm{K}$ and $\mathrm{P}$ levels as independent risk factors for delirium in patients in acute and subacute stages of various diseases who were transferred to a rehabilitation unit. Early identification of the risk factors can be effective in reducing the occurrence of delirium and in increasing the efficiency of rehabilitation.

\section{CONFLICT OF INTEREST}

No potential conflict of interest relevant to this article was reported.

\section{REFERENCES}

1. American Psychiatric Association. Diagnostic and statistical manual of mental disorders. 5th ed. Arlington: American Psychiatric Association; 2013. p. 596-602.

2. Ali S, Patel M, Jabeen S, Bailey RK, Patel T, Shahid M, et al. Insight into delirium. Innov Clin Neurosci 2011; 8:25-34.

3. Inouye SK, Rushing JT, Foreman MD, Palmer RM, Pompei P. Does delirium contribute to poor hospital outcomes? A three-site epidemiologic study. J Gen Intern Med 1998;13:234-42.

4. Kennedy RE, Nakase-Thompson R, Nick TG, Sherer M. Use of the cognitive test for delirium in patients with traumatic brain injury. Psychosomatics 2003;44:283-9.

5. Fearing MA, Inouye SK. Delirium. Focus 2009;7:53-63.

6. Clegg A, Siddiqi N, Heaven A, Young J, Holt R. Interventions for preventing delirium in older people in institutional long-term care. Cochrane Database Syst Rev 2014;(1):CD009537.

7. Inouye SK, Bogardus ST Jr, Charpentier PA, Leo-Summers L, Acampora D, Holford TR, et al. A multicomponent intervention to prevent delirium in hospitalized older patients. N Engl J Med 1999;340:669-76.

8. Inouye SK. The dilemma of delirium: clinical and research controversies regarding diagnosis and evaluation of delirium in hospitalized elderly medical patients. Am J Med 1994;97:278-88.

9. Elie M, Cole MG, Primeau FJ, Bellavance F. Delirium risk factors in elderly hospitalized patients. J Gen Intern Med 1998;13:204-12.

10. Holroyd-Leduc JM, Khandwala F, Sink KM. How can delirium best be prevented and managed in older patients in hospital? CMAJ 2010;182:465-70.

11. Lin Y, Chen J, Wang Z. Meta-analysis of factors which influence delirium following cardiac surgery. J Card Surg 2012;27:481-92.

12. Huai J, Ye X. A meta-analysis of critically ill patients reveals several potential risk factors for delirium. Gen Hosp Psychiatry 2014;36:488-96.

13. van Munster BC, de Rooij SE. Delirium: a synthesis of current knowledge. Clin Med (Lond) 2014;14:192-5.

14. Hwang SW, Kang SW, Kang YG, Choi SG, Lee J, Kim $\mathrm{MJ}$, et al. Risk factors of delirium in elderly inpatients. J Korean Acad Fam Med 2002;23:112-21.

15. Ko HJ, Kim JH. Dementia and delirium among elderly patients in a general hospital medical ward. J Korean Neuropsychiatr Assoc 1997;36:85-91.

16. Yu KD, Lee TJ, Suh YW, Chung SH, Kim EY, Kim HY, et al. Delirium in acute elderly care unit: prevalence, clinical characteristics, risk factors and prognostic significance. J Korean Geriatr Soc 2005;9:182-9.

17. Inouye SK, Charpentier PA. Precipitating factors for delirium in hospitalized elderly persons: predictive model and interrelationship with baseline vulnerability. JAMA 1996;275:852-7. 
18. Pompei P, Foreman M, Rudberg MA, Inouye SK, Braund V, Cassel CK. Delirium in hospitalized older persons: outcomes and predictors. J Am Geriatr Soc 1994;42:809-15.

19. Tsai MC, Chou SY, Tsai CS, Hung TH, Su JA. Comparison of consecutive periods of 1-, 2-, and 3-year mortality of geriatric inpatients with delirium, dementia, and depression in a consultation-liaison service. Int J Psychiatry Med 2013;45:45-57.

20. Roche V. Southwestern Internal Medicine Conference. Etiology and management of delirium. Am J Med Sci 2003;325:20-30.

21. de Lange E, Verhaak PF, van der Meer K. Prevalence, presentation and prognosis of delirium in older people in the population, at home and in long term care: a review. Int J Geriatr Psychiatry 2013;28:127-34.

22. Caeiro L, Ferro JM, Albuquerque R, Figueira ML. Delirium in the first days of acute stroke. J Neurol 2004;251:171-8.

23. Inouye SK. Delirium in older persons. N Engl J Med 2006;354:1157-65.

24. Francis J, Martin D, Kapoor WN. A prospective study of delirium in hospitalized elderly. JAMA 1990;263: 1097-101.

25. Turco R, Bellelli G, Morandi A, Gentile S, Trabucchi M. The effect of poststroke delirium on short-term outcomes of elderly patients undergoing rehabilitation. J Geriatr Psychiatry Neurol 2013;26:63-8.

26. Kim NY, Kim YW. Diagnosis and treatment of poststroke delirium. Brain Neurorehabil 2015;8:59-64.

27. Kim CH, Jon DI, Hong HJ, Jung MH, Park JY, Hong N. The risk factors of delirium in orthopedic elderly patients. J Korean Geriatr Psychiatry 2014;18:39-43.

28. Aldemir M, Ozen S, Kara IH, Sir A, Bac B. Predisposing factors for delirium in the surgical intensive care unit. Crit Care 2001;5:265-70.

29. Kamel HK, Iqbal MA, Mogallapu R, Maas D, Hoffmann RG. Time to ambulation after hip fracture sur- gery: relation to hospitalization outcomes. J Gerontol A Biol Sci Med Sci 2003;58:1042-5.

30. Jung SW, Park SC, Rim JS. The risk factor of delirium after transurethral resection of the prostate. Korean J Urol 2006;47:953-7.

31. Bickel H, Gradinger R, Kochs E, Forstl H. High risk of cognitive and functional decline after postoperative delirium. A three-year prospective study. Dement Geriatr Cogn Disord 2008;26:26-31.

32. McManus J, Pathansali R, Stewart R, Macdonald A, Jackson S. Delirium post-stroke. Age Ageing 2007;36:613-8.

33. Rah UW, Kim YH, Ohn SH, Chun MH, Kim MW, Yoo WK, et al. Clinical practice guideline for stroke rehabilitation in Korea 2012. Brain Neurorehabil 2014; 7(Suppl 1):S1-75.

34. Mysiw WJ, Jackson RD. Differential diagnosis of agitation following brain injury. NeuroRehabilitation 1995;5:197-204.

35. Dickson LR. Hypoalbuminemia in delirium. Psychosomatics 1991;32:317-23.

36. Pol RA, van Leeuwen BL, Izaks GJ, Reijnen MM, Visser $\mathrm{L}$, Tielliu IF, et al. C-reactive protein predicts postoperative delirium following vascular surgery. Ann Vasc Surg 2014;28:1923-30.

37. Ritchie CW, Newman TH, Leurent B, Sampson EL. The association between C-reactive protein and delirium in 710 acute elderly hospital admissions. Int Psychogeriatr 2014;26:717-24.

38. Brauer C, Morrison RS, Silberzweig SB, Siu AL. The cause of delirium in patients with hip fracture. Arch Intern Med 2000;160:1856-60.

39. Schrier RW, Bansal S. Diagnosis and management of hyponatremia in acute illness. Curr Opin Crit Care 2008;14:627-34.

40. Inouye SK, Viscoli CM, Horwitz RI, Hurst LD, Tinetti ME. A predictive model for delirium in hospitalized elderly medical patients based on admission characteristics. Ann Intern Med 1993;119:474-81. 